\title{
EL MERCADO DEL CUERO Y SU ROL COMO FUENTE ALTERNATIVA DE EMPLEO. EL CASO DEL TRABAJO A DESTAJO EN LAS VAQUERIAS DE LA BANDA ORIENTAL DURANTE EL SIGLO XVIII*
}

EDUARDO R. SAGUIER UBA-CONICET

Ultimamente, tanto para Mayo $(1984,1987)$ como para Salvatore y Brown (1987, 1989) - quienes analizan la campiña del Río de la Plata en el siglo XVIII - la clave del dilema de la formación del mercado de mano de obra rural, a diferencia de quienes, como Amaral (1985) y Gelman (1987, 1989), interpretaron que para retenerla era necesario endeudarla, no sólo residiría del lado de la demanda, específicamente el mercado del trigo, sino también del lado de la oferta. Esto ocurriría, según Mayo, Brown y Salvatore, debido al fácil acceso que dicha mano de obra tuvo a otras alternativas de subsistencia (contrabando de tabaco, abigeato, faenas clandestinas de cueros, etc.) y, en consecuencia, a diferentes medios de producción y subsistencia (caballos, ganados, tierra y provisiones como tabaco, sal y yerba), lo cual generó una suerte de superpoblación relativa, y a la consecuente irrelevancia o ineficacia que los mecanismos extraeconómicos tuvieron para retener y disciplinar dicha mano de obra. En la opinión de Salvatore y Brown (1987, 1989), esta irrelevancia obedecía no sólo a la resistencia de los trabajadores precapitalistas (gauchos) a desprenderse de los medios de subsistencia, sino también a la resistencia cultural a cambiar el estilo de vida, los hábitos de trabajo y la conciencia de la noción del tiempo y de la naturaleza del ocio. Ultimamente, Aricó (1987) alegó que la agitación de la cuestión campesina, tal como la formulara Agosti (1951), "... no es nada más que la proyección al pasado de un problema del presente histórico", al apelar a clases y fuerzas sociales y a una cuestión agraria y campesina que nunca habrían existido en el Río de la Plata. Sin embargo, para Salvatore y Brown, el problema residiría justamente en que en el período prerrevolucionario subsistían aún jornaleros poseedores de medios de producción y aparceros y medieros precapitalistas y en que, además, la llamada burguesía agraria no confrontaba aún una clase obrera rural despojada totalmente de

* Ponencia presentada en las IX Jornadas Nacionales de Historia Económica, organiza. das por Argentina de Historia Económica, en octubre de 1988. 
la propiedad de los medios de producción. La aparcería o mediería era visualizada por Marx como una etapa intermedia o de transición entre la renta feudal y la renta capitalista ${ }^{1}$. Para los representantes de las concepciones dualistas, como Prado Junior (1961), el trabajo a destajo era una relación capitalista disfrazada o encubierta, pues los aparceros no pasarían de ser meros asalariados que recibían salarios de manera indirecta, normalizando la producción directa per capita. Sin embargo, para Dos Santos (1972), un representante de la tendencia estructuralista, la aparcería sería visualizada no como una transición, sino como una relación de producción precapitalista y semiservil; la cual, por apoyarse en una división del trabajo entre productores familiares que producían para el autoconsumo, y no expropiaban al trabajador el fruto total de su trabajo, no generaba plusvalía. Por ello, para Dos Santos (1972), la producción capitalista sólo surge con la gestación de plusvalía y con la existencia del trabajador libre, esto es, el trabajador que vende su fuerza de trabajo al propietario de los medios de producción, percibiendo un salario por el alquiler de la misma ${ }^{2}$. Para el caso colombiano, Kalmanovitz (1983) sostiene que "las nuevas aparcerías que surgieron [en la Nueva Granada] podian utilizar parcialmente trabajo asalariado", lo que aproximaba al aparcero "... a la figura del burgués agrario al contratar trabajo asalariado libre y abonar una renta al terrateniente" ${ }^{3}$. El trabajo a destajo y la aparcería o mediería en el nivel de la producción rural se habría desarrollado entonces como alternativa más extendida para maximizar beneficios y minimizar riesgos. En cuanto a su calificación, si bien diversos autores reconocen que en la mayor parte de los casos los acopiadores o contratistas que implementaban estas relaciones sociales de producción eran empresarios no encomenderos, sólo los dependentistas se atreverían a aseverar que estos últimos fueran arrendatarios capitalistas. De igual manera, en lo que hace a la calificación del salario, si bien es indudable que la relación social que prevalecía en la producción de bienes exportables (cueros) era el trabajo a destajo, sólo los dependentistas se animarían a asegurar que la naturaleza de ésta fuera la de un salario capitalista.

La dificultad de esta polémica residiría, a mi juicio, en la distinta naturaleza del tipo de tareas discutido. A diferencia de lo que sostiene Sala de Tourón (1967), creo que hay una distinción sustancial entre la condición del peón contratado para una corambre y la del peón de estancia, pues si bien el tipo de remuneración era similar (en dinero o en especie), lo que se remuneraba era notoriamente distinto. Mientras que a un puestero de

1 Karl Marx, El Capital, Libro I, Sec. VI, cap. XXI

2 Dos Santos (1972), 146.

${ }^{3}$ Kalmanovitz (1983), 74. 
estancia se lo contrataba en forma permanente y se le pagaba un salario por tiempo (un promedio de 8 dólares por mes), a un peón changador se lo contrataba transitoriamente y se le pagaba, según la propia Sala (1967) reconoce, un salario o jornal por pieza faenada; con el cual, como, veremos, a veces doblaba el sueldo mensual de un peón y podía llegar a doblar el sueldo mensual de un capataz de estancia, quien nunca ganaba más de 12 pesos mensuales 4 .

En las corambres o vaquerías, el comerciante o acopiador de pieles o cueros se veía obligado a lidiar en un negocio donde prevalecía, aunque en forma primitiva, un embrionario mercado a término, el cual, a su vez, alteraba las relaciones sociales de producción tradicionales impulsando el trabajo a destajo o por piezas y una incipiente división del trabajo. En lo que hace a la naturaleza del mercado del cuero, los precios se fijaban generalmente por adelantado mediante escritura pública. Tanto la fijación de los precios como la cláusula de exclusividad durante el término del plazo contraído en los créditos de compra o habilitaciones, confería a las relaciones sociales y económicas en la producción de cueros una naturaleza oligopsónica $^{5}$. De esta forma, la especulación creaba, parafraseando a

4 Sala de Tourón et al. (1967), 156.

5 Las diferentes series de precios habrán de ser promediadas mediante el método de los números-índice o mediante tasas. Hamilton (1947) y Levene (1962) calcularon sus númerosíndice a través de la simple media aritmética. En su lugar, Broide (1951) utilizó el promedio per menos sensible a los desvíos extremos. Por el contrario, Nadal (1959) empleó medias móviles, donde las variaciones las refiere no a un punto fijo inicial, sino a los períodos precedentes en cada caso. Los números-índice o relativos simples dan la evolución en el tiempo del cociente de los valores de cada serie dividido por el valor correspondiente $a$ un período que se toma como base. Como base de los índices habremos de tomar los valores que no ofrezcan alteraciones bruscas con respecto al promedio de la serie. Los criterios metodológicos a instrumentar en la selección del período base varían según el interés perseguido por el investigador. Para levene (1962), los precios base son los precios correspon. dientes a los períodos de paz, que sirven de punto de comparación con los precios de los años de guerra. Las guías marítimas, las escrituras de factoraje y las facturas incorporadas en los litigios judiciales nos brindan una información invalorable. De aqui que, a los efectos de poder seleccionar el período base más útil para el estudio de las crisis cíclicas, sea preciso volver al método instrumentado por Levene (1962), manteniendo el año calendario como la cronológico más operacionalizable. Para calcular el movimiento estacional desvíos estacionales y los desvíos mensuales medios. Los primeros tratan de osvíos entre la media mensual más baja y la media mensual más alta, y los segundos consisten en las desviaciones de las medias mensuales respecto de las medias anuales. Respecto a la ponderación, los criterios para seleccionar el método más conveniente para estimar series incompletas varian de acuerdo a los intereses metodológicos de cada investigación en particular. En virtud de la naturaleza incompleta de la estadística del comercio exte rior porteño, Broide (1951) eligió una ponderación conjetural de tipo directo, que consiste en suponer, fundándose en los cálculos de Burgin (1946), que los cueros formaban aproximadamente la mitad de los envíos al exterior, dividiéndose la otra mitad (1951) calculó un índilanas, sebo y tasajo. Respecto a la composición de los cueros, 
Hilferding (1910), un precio para cada pesada del cuero y para cada momento del año, al extremo de convertirse en un mercado a término que le daba al acopiador "la posibilidad de beneficiarse de las consecuencias eventuales del movimiento de los precios, y de cargar a la especulación el riesgo por los cambios de preciom 6 .

Para la determinación del precio de los cueros existían en la segunda mitad del siglo XVIII dos tipos de mercados, el de contado, o de ajuste rápido, y el mercado de futuros o a término, o de ajuste lento. En el primero, las partes acordaban la entrega de una cantidad de cueros a un precio, realizando la entrega en forma inmediata o efectiva. En el segundo, las partes acordaban entregar o recibir una cantidad de cueros en un momento específico del futuro ${ }^{7}$.

Las frecuencias de las corambres fluctuaban sólo dentro de la estación invernal. Los únicos que no respetaban esta restricción estacional y vaqueaban en verano eran los que faenaban cueros clandestinamente, ya que poco les importaba que en las disparadas de la hacienda se murieran los terneros recién paridos. Ya en el siglo XVII se empiezan a observar las primeras experiencias de mercado a término en la producción pecuaria. Gonsález (1957) relata cómo se comienza a comercializar el cuero a entrega futura, es decir, antes de la corambre, colocando la producción a los dueños de los navíos de registro. Esto es aceptado por los capitanes de los barcos, puesto que se aseguraban la puntualidad de la entrega y el conocimiento del costo de sus insumos.

Los precios de futuros tendían a ser más elevados que los de contado debido a gastos extras en intereses y almacenamiento. Por ejemplo, si bien

ce de precios del cuero integrado por las subseries de los cueros de buey, yeguarizo y vaca, que los promedió con el término medio de los índices de los otros productos. En su lugar, en nuestra serie de precios del cuero la información se encuentra desagregada en cueros de toro y novillo. Cada una de las mismas se encuentra, a su vez, desagregada a comienzos del siglo xvili a tenor de la dimensión de cada unidad (largo por ancho) en varas y, a partir de mediados del mismo siglo, a tenot del peso en libras castellanas. De un total de 604 cueros vacunos obtenidos en una vaquería practicada en la Banda Oriental se obtuvieron, a fines del siglo XVIII, 247 cueros de 40 libras, o el 41 por 100; 169 de 35 libras, o el 28 por 100; 94 de 30 libras, o el 16 por 100, y 94 de menos de 30 libras, o el 16 por 100 (AGN, Sala IX, Hacienda, leg. 6, exp. 120). Para prolongar la línea que ilustra la tendencia de este fenómeno particular, debemos adoptar entonces como supuesto las proporciones mencionadas, aunque estén apoyadas en una fuente que atañe a una sola parte de la región rioplatense. En efecto, extrapolando para el resto de la estadistica anual de cueros exportados la distribución de cueros por escala de peso hechos en una corambre específica de un año en particular, estaremos en condiciones de justipreciar el valor verdadero de las exportaciones de cueros hasta hoy conocidas. La tabla ilustra estos mismos valores.

6 Hilferding (1985), 164.

7 Ignoramos si este embrionario mercado a término era implementado como seguro o cobertura contra las oscilaciones del precio del cuero. 
los cueros de 25 a 40 libras tomados en marzo de 1772 para dentro de seis y doce meses de plazo costaban a razón de 4 y 11 reales, aquellos tomados un mes antes para dentro de diez y veintiún meses costaban a razón de $6 \mathrm{y}$ 15 reales, respectivamente ${ }^{8}$. El premio o diferencia entre el precio actual en efectivo y el precio de los futuros obedecía a oscilaciones en: 1) la oferta y 12 demanda del cuero; 2) la provisión de carretas y lanchones, y 3) la oferta y demanda de bodega marítima. En el ejemplo mencionado, la prima o premio entre ambas contrataciones alcanzaba a dos reales por cuatro y diez meses de diferencia que había entre una y otra compra a término. Al acercarse la fecha término, ambos precios se iban igualando por cuanto los costos de almacenamiento y la tasa de interés iban perdiendo importancia. Si los precios de los meses más lejanos se cotizaban más alto que los cercanos, se podría decir que existía un mercado normal, por reflejar éste los costos de almacenamiento e interés. En cambio, si ocurría lo contrario, se podría decir que existía un "mercado invertido". Esto ocurría sólo en casos de fuerte presión de la demanda en el corto plazo.

Observando detenidamente la tabla I, descubrimos que, a diferencia del estancamiento sostenido por Romano (1963), se produce a mediados del siglo XVIII un sostenido aumento del precio del cuero, partiendo en 1745 de un precio de 15 reales para el cuero de toro y 12 reales para el de novillo (ambos de 3 varas de longitud por 2 varas de ancho), hasta alcanzar en

\section{TABLA I}

Mercurial del precio del cuero, 1745-1759

(Medido en varas y valuado en reales)

\begin{tabular}{|c|c|c|c|c|c|c|c|}
\hline & \multirow[b]{2}{*}{ Atios } & \multicolumn{3}{|c|}{ Cueros de toro } & \multicolumn{3}{|c|}{ Cueros de novillo } \\
\hline & & 3 varas & $25 / 6$ & $23 / 4$ & 3 varas & $25 / 6$ & $23 / 4$ \\
\hline 1745 & , & 15 & & 12 & 12 & & 11 \\
\hline 1748 . & 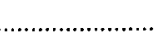 & 16 & 14 & 10 & 12 & 10 & \\
\hline 1750 & .......................... & 18 & 16 & & 14 & 12 & \\
\hline 1752 & …......................... & 19 & 17 & & 14 & & \\
\hline 1753 & ……................. & 20 & 18 & 16 & 16 & 14 & 12 \\
\hline 1759 & ....................... & 21 & & & & & \\
\hline
\end{tabular}

Fuente: AGN, Protocolos, Registro 2, 1745, f. 63v.; R. 4, 1748, f. 22; R. 4, 1750, f. 155; R. 4, 1752, f. 36v.; R. 4, 1753, f. 105v., y R. 1, 1759, f. 214v.

8 AGN, Sección Tribunales, Protocolos, Registro 5, 1772, fs. 96, 112v., 109v., 152v., 166v. y 180 . 
1753 los de 20 y 16 reales, respectivamente, o el 33 por 100 de aumento. Estos precios tienen la virtud de mantenerse hasta la entrada de España en la Guerra de los Siete Años, a fines de 1761, fecha en que sufren una caída vertiginosa.

Con la Paz de París, declarada en 1763, el precio del cuero experimenta un boom que supera los precios alcanzados en la preguerra. Efectivamente, según la tabla II, el cuero de toro de 40 libras, equivalente al que mide 3 varas por 2 varas, alcanza el precio de 23 reales, mientras que el de 30 libras, equivalente al de novillo de 3 por 2 varas, alcanza el precio de 20 reales. Estos precios, a medida que la intensa demanda de posguerra se fue cubriendo, en lugar de mantener su nivel, sufren un progresivo descenso, hasta tocar en 1769 el piso más bajo, con 9 reales el cuero de 40 libras y $31 / 4$ reales el cuero de 25 libras, es decir, una baja del orden del 61 y 86 por 100 , respectivamente. Al año siguiente, en 1770 , el precio del cuero sube a 5 1/2 reales el de 25 libras y 14 reales el de 40 libras, es decir, un alza con relación al año precedente del orden del 50 por 100 . A partir de dicho año y hasta la participación de España en la guerra contra Inglaterra o de la independencia de Estados Unidos, en 1779, el precio del cuero se mantuvo estancado debido, aparentemente, a la intervención del mercado de futuros. Con la participación de España en la guerra de la independencia de Estados Unidos, el precio del cuero cayó a 8 reales el de mayor calidad. Finalmente, durante las guerras napoleónicas, debido al permiso real de comercio con colonias extranjeras y en buques neutrales, su valor se mantuvo en los 12 reales por unidad'.

En el precio de exportación del cuero deben computarse los costos de transacción incurridos por los acopiadores, pues los fletes terrestres y fluviales (un real o el 12 por 100 en concepto de flete para aquellos cueros transportados en lancha desde Buenos Aires hasta Montevideo) incluían aquellos gastos necesarios para poder acondicionar los cueros en los puertos de salida. Cada carretero que transportaba los cueros hasta los puertos de cabotaje debía llevar guías del número de cueros que condujere cada carreta, precaviendo de ese modo que se extrajese ilegalmente ningún cuero por el camino de tránsito. Más aún, a fines de siglo se estableció por bando que las guías debían llevar consignadas las marcas de los cueros respectivos. En el caso de los cueros puestos en Montevideo, el acopiador debía pagar, amén del flete mencionado, dos reales en concepto del derecho del Ramo Municipal de Guerra, el cual suponía un 25 por 100 del valor del cuero, aforado a un peso cada unidad (que no se cobró en Montevideo hasta 1779), y un 4 por 100 en concepto del Ramo de Alcabala ${ }^{10}$.

9 AGN, Sala IX, Hacienda, leg. 97, exp. 2521, f. 87.

10 AGN, Sala IX, Tribunales, leg. T-6, exp. 5. 


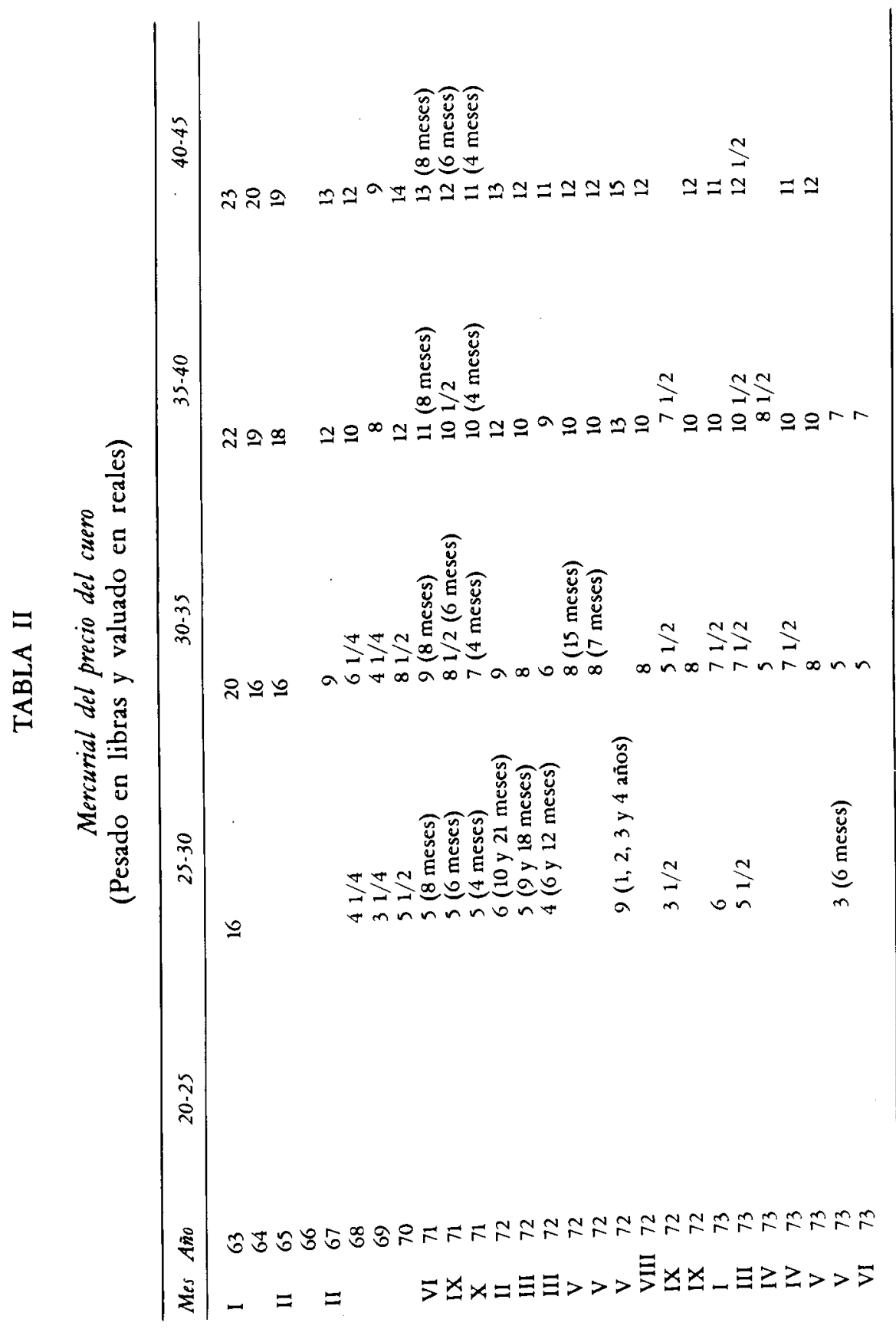




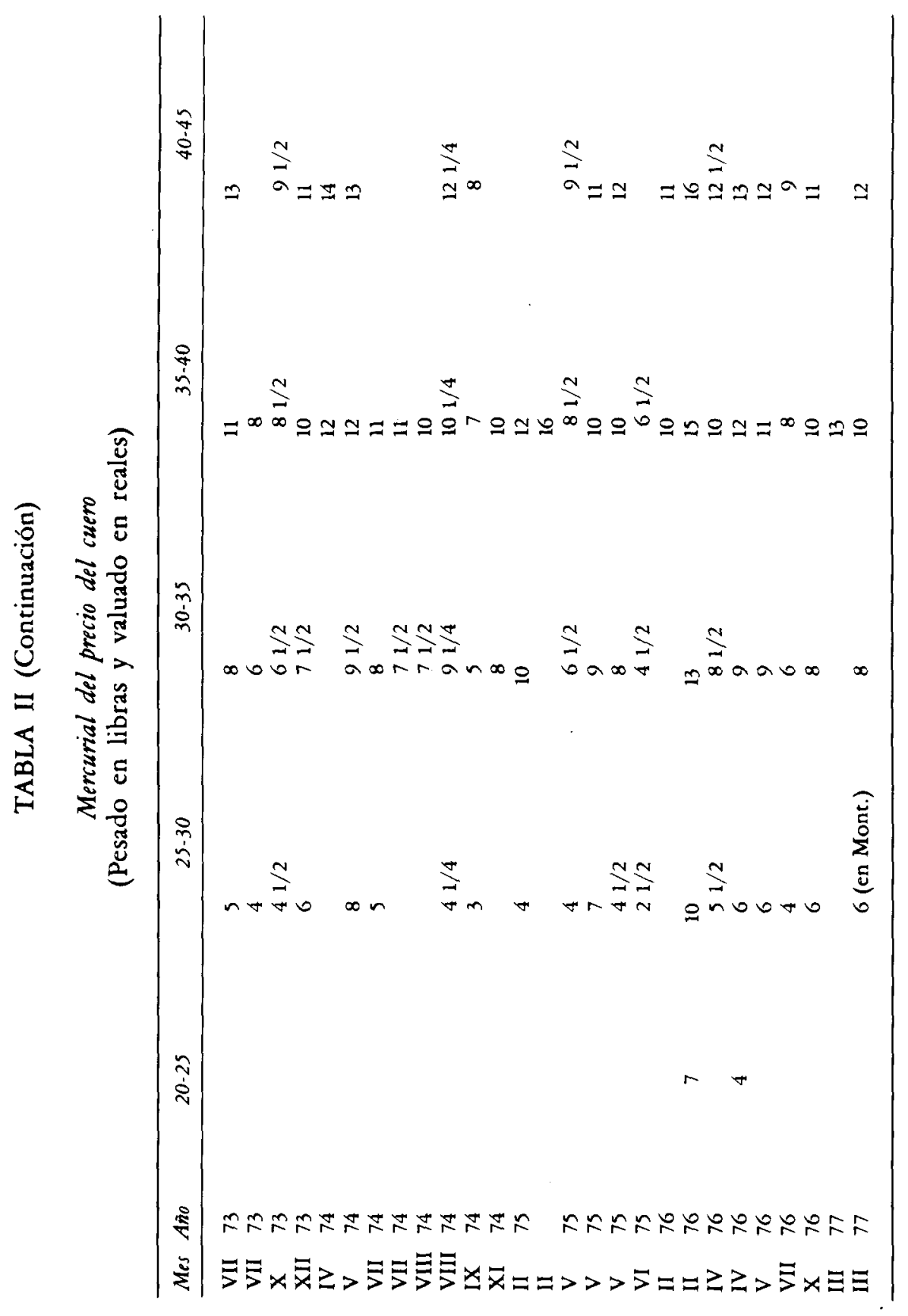


Juntas, las tres partidas constituían un 41,5 por 100 del valor del cuero a su salida de América. En el caso de los cueros remitidos desde Buenos Aires a Montevideo, era preciso que antes de embarcarlos en las lanchas del río se reconociera si estaban de recibo y se practicara, además, su pesaje y romaneaje. Para esta tarea se requería que al menos hubiesen pasado tres días desde la última lluvia, de modo que los cueros presentaran menos del 10 por 100 de humedad ${ }^{11}$. Por cueros a estilo de embarque se entendía aquellos de 40 , 50 y hasta 70 libras, pues nunca "... se ha renido por cuero comerciable los de becerro, respecto a ser chicos, y no tener peso regular" ${ }^{12}$.

Si, a su vez, estos cueros debían ser exportados a España, el comerciante exportador, y no ya el acopiador, debía pagar los gastos por los estibadores que hacían el arrumaje y acomodo de los cueros en la bodega de los barcos, el flete Río de la Plata-Cádiz, el derecho de entrada en España, la comisión y el seguro ${ }^{13}$. Teniendo en cuenta que el flete del Río de la Plata a Cádiz oscilaba entre 4 reales plata por pesada de 35 libras, en tiempos de paz, que corresponde al 50 por 100 aforado a un peso (8 reales) cada cuero, y 24 reales plata en tiempos de guerra; que el derecho de entrada en España alcanzaba a $21 / 5$ reales por pesada de 35 libras (4 maravedíes de vellón por libra, o 140 maravedíes, o 4 reales y 4 maravedíes de vellón por pesada de 35 libras), que corresponde a algo más del 25 por 100 aforado a peso cada cuero; que la comisión respectiva se estilaba en el 4 por 100 sobre su precio en el puerto de salida ( 16 reales plata) o $3 / 4$ de real por cada unidad, o el 9 por 100; que el seguro alcanzaba al 3,50 por 100 sobre un aforo de 18 reales provinciales o $141 / 2$ reales plata, igual a $1 / 2$ real de plata $o$ 6,25 por 100 , siempre con referencia a la unidad, concluimos que los gastos de comercialización (derechos de entrada más comisión y seguro) de un cuero de 35 libras que costó 12 reales plata alcanzaba promedio entre 8 reales plata o el 90 por 100, en tiempos de paz, y 27 reales plata en tiempos de guerra ${ }^{14}$. Asimismo, si se quería reexportar dicha mercancía a reinos extranjeros se debía pagar el derecho de salida de España a razón de 9 reales de vellón por cuero, o el 15 por 100 sobre el avalúo de 60 reales de

11 .... respecto de que el crítico de la estación del tiempo no permite perder minuto bueno para pesar y embarcar en dichas urcas que resultaría en grande perjuicio de la Real Hacienda pesarlos en el segundo o tercer día de haber llovido por la mucha humedad que en el invierno conserva este género como en el día se ve pues después de tres días buenos de Pamperos no he permitido se pesen hoy porque aún tiene más del 10 por 100 los cueros de humedad de lo que ha llovido» (AGN, Sala IX, Hacienda, leg. 28, exp. 696).

12 AGN, Sala IX, Tribunales, leg. S-11, exp. 8, f. 46.

13 Gelman (1983), 114-115, y AGN, Sala IX, Tribunales, leg. T-6, exp. 5.

14 AGN, Sala IX, Hacienda, leg. 26, exp. 653, f. 10; Tribunales, leg. T-6, exp. 5, y Garavaglia (1977), 93. 
vellón por cuero, y el flete de Cádiz al puerto extranjero, que, sumado a los derechos de entrada, comisión y seguro, alcanzaba al 97 por 100. Sumando al costo del cuero sus gastos de comercialización, que oscilaban entre 13 y 17 reales plata, y considerando que el precio del mismo en Espana fluctuaba alrededor de los 30 reales plata, debemos concluir que la exportación legal de frutos del país sólo era lucrativa en tiempos de paz ${ }^{15}$.

Por cierto, considerando estos altos costos de comercialización, sólo en tiempos de guerra, mediante faenas clandestinas o exportando ilegalmente a los reinos extranjeros, es decir, con operaciones donde se salvaban todos los gravámenes fiscales, podía alcanzarse una tasa de ganancia razonable. En un documento de época se aclara que los cueros extraídos por los portugueses y fraudulentamente conducidos hasta Río de Janeiro, y de ahí a Lisboa, pagaban el 4 por 100 por un derecho que llamaban de baldeación, y luego el quinto por el derecho de los géneeros que se embarcaban, que correspondía al 20 por 100 :

... con que importando las dos partidas 24 por 100 , es visto que los extranjeros ahorran por aquella vía [fraudulenta], un $15 \mathrm{o}$ 16 por 100 , y que el Real Erario y los ramos particulares se privan de un 39 ó 40 por 100 que se dejan de contribuir por prohibir tan estrechamente estas faenas ${ }^{16}$.

Como consecuencia directa de la vigencia de un mercado a término para la fijación del precio del cuero, los empresarios de vaquerías o corambres se vieron obligados a maximizar la rentabilidad de sus empresas dividiendo la fuerza de trabajo a su cargo según las diversas tareas que las comprendían; componiéndose esencialmente de baqueanos, desjarretadores, desolladores, barraqueros, bomberos y achuradoras. El personaje central en esta empresa era, indudablemente, el vaquero, desjarretador o faenista, habiendo por vaquería un promedio de dos o tres vaqueros acompañados por un solo peón caballerizo y entre tres y diez peones desolladores ${ }^{17}$. La retribución de cada una de dichas tareas variaba por cuanto el tiempo y la habilidad requeridas para desempeñar cada una eran también distintas.

La desigual inversión en tiempo y habilidad para cada tarea hacía necesaria entonces una primitiva diferenciación salarial; aquellas tareas más riesgosas y que requerían de mayor vaquía (calificación), como la del vaquero que desjarretaba y acodillaba el animal, debían ser mejor pagadas que las de menor riesgo, como, por ejemplo, la del peón que sólo cuereaba al vacuno

15 Gelman (19) ), 114-115.

if AGN, Sala IX, Tribunales, leg. T-6, exp. 5.

17 Archivo General de la Nación (AGN), Sala IX, Hacienda, leg. 4, exp. 61, f. 329. 


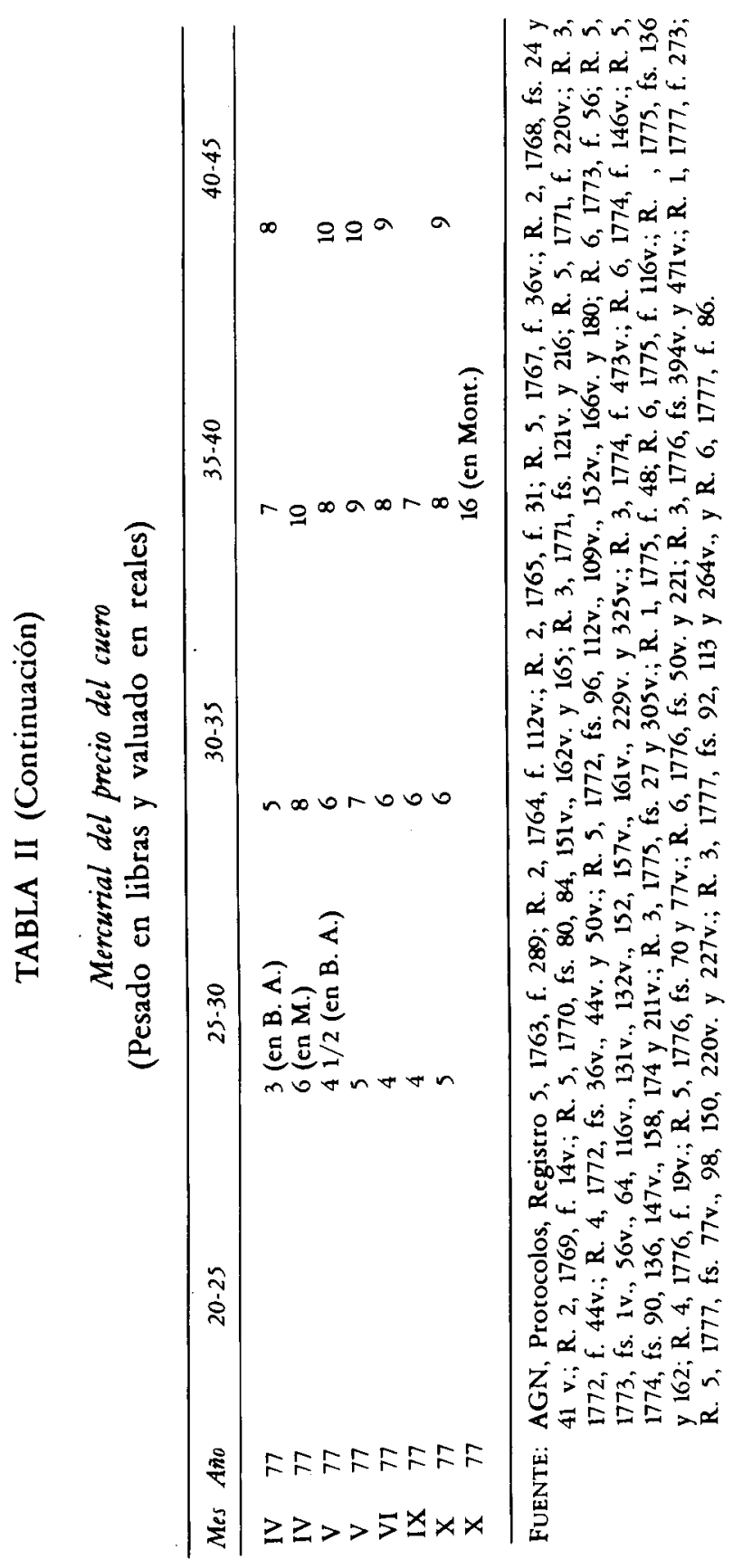


y estaqueaba y marcaba al cuero, o la del barraquero que simplemente recogía, desgarraba, limpiaba, clasificaba, apilaba y prensaba los cueros ${ }^{18}$. Si bien, aparentemente, el vaquero recibía por unidad de cuero producida menor jornal ( $1 / 2$ real por cuero) que el peón o el barraquero, quienes cobraban entre un real y medio y dos reales por cuero construido, en la totalidad de la jornada el vaquero doblaba o triplicaba los ingresos del peón. Los sueldos de los barraqueros se pagaron siempre por las papeletas que los vaqueros les daban por el tiempo de sus servicios, expresando en ellas lo que habían invertido, a razón de cuánto por mes o por cuero, y qué número de cueros habían tenido a su cargo ${ }^{19}$. Por ejemplo, en la estancia "La Calera", cada peón desollador recaudaba entre 8 y 18 pesos por mes, mientras que el vaquero Martín Cuello, el que menos toros había desjarretado, recaudó $\$ 19$ y 3 reales, y Tomás Díaz, quien había alcanzado el récord, recaudó $\$ 33$ y 3 reales por mes.

La diferencia entre peón y vaquero obedecía al hecho de que la cantidad de animales que cada vaquero desjarretaba en una jornada de labor doblaba o triplicaba la cantidad de animales que un peón podía alcanzar a cuerear o apilar en el mismo tiempo. Como promedio, cada vaquero desjarretó en 1769, en la estancia mencionada de los jesuitas expulsos, entre 200 y 600 toros por mes. El récord fue alcanzado por el vaquero Tomás Díaz, quien desjarretó 1.069 toros en tres meses; seguido por Pascual Moroti, con 894 toros, y por quien menos cueros hizo, el vaquero Martín Cuello, con 620 toros, todos en igual período 20 .

Como a los peones se les pagaba por cuero, ya fuese de toro o novillo y chico o grande, es muy probable que los vaqueros prefirieran reducir sus riesgos y acelerar la faena aprovechando los días o semanas de buen tiempo, desjarretado aquellos vacunos que les ofrecían mayor resistencia y esfuerzo; en otras palabras, la velocidad de la faena dependía de la consistencia del suelo y de la edad y gordura de los vacunos. Es sabido que lluvias excesivas provocaban tal humedad en el suelo que impedían que los vaqueros maniobraran con soltura sus cabalgaduras. Por otro lado, el ganado joven y gordo le exigía al vaquero mayor velocidad y destreza.

Por supuesto, los acopiadores preferían aminorar sus costos, haciendo recaer el peso del trabajo en núcleos o reservorios de mano de obra semiesclava, conchabando en forma colectiva partidas de indios Tapes o Minuanes o, cuendo el acopiador era un militar, recurriendo al auxilio de soldados y

1* Según Coni (1930), el Real Asiento de Inglaterra declaraba como gasto el salario de un vaquero, el cual desjarretaba a razón de $\$ 50$ (400 reales) cada mil toros, o $2 / 5$ de real cada cuero.

${ }_{19}$ AGN, Sala IX, Hacienda, leg. 73, exp. 1945, f. 2.

20 AGN, Sala IX, Hacienda, leg. 4, exp. 61, f. 329. 
oficiales en lugar de changadores mestizos, a los que había que pagar con jornales individuales ${ }^{21}$. Así, por ejemplo, en 1730, el capitán Luis de Sosa Mascareñas, alcalde de la Santa Hermandad, declaró ante el Cabildo de Montevideo que las ranchadas de los changadores atraían hacia ellos a muchos de los indios reducidos en Santo Domingo Soriano, con sus mujeres e hijos, para peones de a pie y cocineras y lavanderas; y al no faltar los cielitos (bailes) y los beberajes, "empezaban las mujeres a descomponerse con los troperos" 22 .

Revelando indirectamente la discriminación de que eran objeto los indios, en el monto de la paga, por parte de los faeneros, Juan Bautista Dargain pide en 1792 licencia para vaquear en la otra banda bajo la excepcional condición de

... que en estas faenas he de emplear para peones... a los indios del Pueblo de Yapeyú que con permiso de su Corregidor Cabildo y Administrador se me presentasen a conchavo a los cuales he de pagar en igual forma que a los peones Españoles que conchabase para el mismo efecto ${ }^{23}$.

Se sabe también cómo las vaquerías o corambres, donde se retribuía con un jornal a destajo, contribuyeron en gran medida a la disolución de las escasas reducciones indígenas existentes aún en el siglo XVIII. Ya a comienzo de siglo, el procurador general llamaba la atención del Cabildo de Buenos Aires sobre una estancia poblada por portugueses; y declaraba que los mismos, con ser inhábiles para vaquear, se valían de los indios Minuanes y de los peones de Santa Fe, llegando incluso a valerse de peones tucumanos $^{24}$. Al entregarse a la matanza de ganados para servir a los intereses de los acopiadores de cueros y obtener en retribución toda suerte de abalorios, los indios de las misiones jesuíticas

... no atendieron ya sus telares, siembras, y otros trabajos establecidos y todo lo que antes se llevaba y gobernaba, por unas muy escrupulosas reglas, se redujo a confusión y trastorno y aún se acreditó, que en los años de 1768 y 1769 no enviaron efectos algunos para el pago de tributos y demás indispensables gastos, sino once pueblos, y éstos en muy corta cantidad ${ }^{25}$.

21 Porto (1943), 207-215.

22 Assuncao (1978), 392.

23 AGN, Sala IX, Hacienda, leg. 66, exp. 1769, f. 1.

24 Assuncao (1978), 392. por Barrios Pinto (1967), 71. 
Amén de los indios, a los acopiadores (empresarios exportadores de frutos) les convenía, para aminorar sus costos y maximizar sus ganancias, entrar en tratos con oficiales a cargo de guarniciones militares, aprovechando así a la soldadesca ociosa. En la Guardia del Paso del Rey (Banda Oriental), Andrés Fernández, natural de la Villa Rica y vecino del Camacuá, mayor de treinta años, de oficio labrador, que lo prendió la gente de la partida de don Antonio Pereira más allá del Fraile Muerto, dijo

... que siempre han visto que las mayores cogidas de ganado que se hacen y introducen en aquellos dominios, son por los capitanes, coroneles, y demás personas de distinción, constándole asimismo que muchas ocasiones salen las tropas cogedoras de ganado, auxiliadas con soldados y oficiales, como de ordinario suele hacerlo el Capitán Francisco Alvarez con su gente ${ }^{26}$.

En su lugar, las vaquerías y recogidas de ganado alzado de la banda occidental del Río de la Plata se frustraban cuando existían rumores de malones indígenas o escasez de caballos; y en esos casos se extraía siempre el ganado de las estancias, aunque sus dueños se quejaran de que contaban con escaso ganado y que era flaco el poco que tenían. La extracción la practicaban los matanzeros o compradores de reses formando cinco partidas para cada uno de los cinco partidos (jurisdicciones) de la campaña, comenzando con el pago más próximo y, a medida que los pagos más cercanos eran trajinados, les seguían los demás pagos más lejanos, de modo que, una vez abastecida la ciudad con reses del primer pago, "... días antes que se experimentase el clamor del pueblo estuviese proveída con las del segundo pago, y así hasta el último" 27 .

Por otro lado, la relación que mantenían el personal de las vaquerías o corambres con los medios de producción era desigual, por cuanto cada uno de ellos poseía con intensidad diversa algún medio de producción. En las corambres o faenas de hacer pieles, los vaqueros eran provistos por el empresario acopiador con medias lunas para desjarretar los animales, con cañas tacuaras para calzar las medias lunas, y con espadines para acodillarlos, pero no de los caballos, que eran de su propiedad. Las cañas tacuaras en que se engarzaban las medias lunas era producidas en Corrientes, donde la Mayordomía de la Iglesia Catedral se encargaba de su distribución, vendiéndose a 3 reales cada una. Mas no siempre era éste el precio normal. En los reparos puestos por el Cabildo de Corrientes a la rendición de cuentas que hiciera en 1781 el mayordomo de la Iglesia Catedral, doctor don

26 AGN, Sala IX, Hacienda, leg. 24, exp. 569, f. 14

27 Idem. 
Antonio Martínez, los cabildantes le reprochaban que en tiempos pasados se vendían las tacuaras "... cuando más caras, a 20 pesos o 160 reales cada carretada de a 50 tacuaras", o 3 reales cada una. Dicho párroco, según los cabildantes,

"... no sólo carga a 4 reales cada tacuara, sino también carga el costo de peones, gastos de yerba, tabaco, alquileres de bueyes, caballos, y erramientas, de manera que cada tacuara sale cuando menos a dos pesos, siendo constante que el vecindario acarreó a su costa dichas tacuaras hasta la cercanía de esta ciudad cuio exceso en el valor de las tacuaras es tan perjudicial a la Iglesia, que se conoce palpablemente el artificio con que fundo dichas cuentas, esparciendo en diferentes partes el costo de dichas tacuaras, para no ser conocido esta maldad» 28 .

Los caballos eran su principal instrumento de trabajo, al cual adiestraban y enseñaban especialmente para la tarea de faenar, enlazar y pechar, en la cual ganaban a razón de medio real por cuero pagaderos en especie (yerba, tabaco). Incluido en el salario por cuero producido estaba la reposición por el desgaste o amortización sufrido por su instrumento de trabajo: la tropilla de caballos. Por el contrario, los peones destinados a desollar los animales carecían de caballos propios y operaban como caballerizos, cuidando de las cabalgaduras de los vaqueros y ganando a razón de dos reales por cuero desollado. Aquellos peones que estaquillaban, apilaban, sacudían y prensaban los cueros también ganaban a razón de dos reales por cuero ${ }^{29}$.

28 AGN, Sala IX, Tribunales, leg. M-13, exp. 7, f. 16

29 Respecto a los jornales pagados por cada cuero, véase AGN, Sala IX, Hacienda, leg. 6, exp. 120. En las satisfacciones dadas al Ramo de las Temporalidades, por cargos suspendidos a las cuentas que tenía rendidas don Pedro Díaz de Vivar, éste declara en 1803 nombre de María Antonia de Achucarro, viuda de Melchor de Viana, administrador que fue de dicho Ramo, que: "Es del cargo de todo hacendado entregar al Baquero dos medias lunas para que desgarrete el animal: asimismo se le administra dos hojas de espadón con las que forman igual número de chusas para que lo acodillen y le den muerte: consiguientemente se le pasan uno o dos peones destinados de caballerizos para el cuidado de las cabalgaduras de los baqueros que éstos trahen suyas propias, y mudan alternativamente pues no cualquiera sirve a ese efecto, y es urgente esté diestra y enseñada a él, por ser contingente y peligrosa esta operación: conseguida la acción de desgarretadores y muerto el animal, envían los peones a sacar la piel de él, administrándoles los cuchillos necesarios, siendo de la obligación de este individuo el estaquearla y figurarla. Luego entra el individuo o individuos de idoneidad que se titulan Barraqueros, al recojo y reconocimiento de las pieles, si están bien acondicionadas y enjutas, y de recibo, y estándolo se le abona al peón, haciéndole conducir de cuenta del dueño de la faena a la barraca del depósito, donde también los barraqueros aprensan las pieles y acondicionan. Todo lo expuesto es indispensable y urgente, y de práctica, y para dichas operaciones el gasto de yerba mate y tabaco en rama; y si no véase los documentos referidos de fs. 476 y 477 , que son los contratos" (AGN, Sala IX, Hacienda, leg. 44 , exp. 1159 , f. 22) 
En cambio, los caballerizos, y a veces los barraqueros, ganaban un salario por tiempo entre 8 y 10 pesos cada mes. Las achuradoras eran casi siempre las mujeres y los niños que acompañaban a los peones en las carretas de cada expedición montada al efecto, las que asimismo operaban como cocineras y lavanderas.

Si bien el caballo era un instrumento de trabajo para vaquear, recoger, apartar, enlazar, bolear, arriar, pezcar, pisar ladrillo, vender al menudeo o moler trigo, cuya propiedad convertía a su poseedor en un propietario de medio de producción, también es cierto que el caballo también era un medio de transporte individual que le permitía a su propietario gozar de una mayor movilidad para vender, ocasionalmente, su fuerza de trabajo ${ }^{30}$. Poseía, a su vez, el caballo la ventaja de poder reproducir su fuerza de trabajo en forma natural sin requerir de gasto alguno, salvo el fondo de reposición por la brevedad de su ciclo de vida útil.

Como es sabido, el acopiador o capitalista pagaba por la fuerza de trabajo contratada mucho menos que el valor producido por dicho trabajo. En nuestro caso de la corambre, por cada cuero producido y apilado en la barraca, el acopiador obtenía entre 10 y 23 reales, según su peso o tamaño, y desembolsaba por él una suma de costos fijos y variables. Los costos fijos estaban constituidos por los medios de producción (desjarretadores, espadines, cuchillos y estacas), los cuales se prorrateaban entre la totalidad de las unidades producidas. Por ejemplo, en la hechura o construcción de 2.350 cueros se insumieron, en 1769 , tres carros completos de estacas y, en 1784, para la construcción de 1.031 cueros se insumieron $41 / 2$ docenas de cuchillos y solamente una media luna, a un costo entre 12 y 21 reales cada docena de cuchillos ${ }^{31}$. El costo variable estaba constituido por la fuerza de trabajo incorporada al producto, consistente en los vaqueros, los peones y los barraqueros, trabajando a razón de medio real por cada cuero los primeros y dos reales por unidad los otros, más el costo de las vituallas

${ }^{30}$ En las recogidas de ganado o rodeos prevalecía también una primitiva división del trabajo, según que se marcara, apartara, castrara, señalara, curara o simplemente revisara o contara. El caballo para trabajar en rodeo también debía ser adiestrado en enlazar, echar al medio y pechar. Cada paisano llevaba su remuda, pues el continuo correr a toda rienda, pararse, tornear, pechar, aguantar cimbrones de lazo, cansaban mucho al animal. Término medio, cada yeguarizo aguantaba dos o tres horas, según fuera la edad de los vacunos a trabajar, el estado de gordura y la consistencia del suelo. Tengamos en cuenta que, como bien lo explica Terrera (1970), apartar un ternero era una cosa y apartar novillos gordos otra, y que el cansancio del caballo aumentará o disminuirá según la hacienda y el mismo terreno. A animales gordos y jóvenes, mayores corridas; a hacienda flaca y vieja, menor esfuerzo. Lo propio ocurre con el terreno: si está blando será más pesado, y si seco, menor esfuerzo para el caballo que trabaja [Terrera (1970), 342].

31 AGN, Sala IX, Hacienda, leg. 4, exp. 61, f. 329; leg. 29, exp. 747, f. 17; leg. 42, exp. 1075 . 
(yerba y tabaco), que oscilaba con el número de peones empleados y el costo de flete, fluctuando este último con la mayor o menor distancia a los embarcaderos más cercanos ${ }^{32}$. Los costos variables estaban constituidos por el alquiler de las carretas o flete ${ }^{33}$.

32 Si tenemos en cuenta que por cada cuero producido, que el acopiador vende a 12 reales, tuvo que desembolsar $81 / 2$ reales en concepto de costos variables y $11 / 2$ reales en concepto de costos fijos, habrá entonces obtenido un plusvalor del orden de los 2 reales. De aquí entonces que si quisiéramos medir la tasa de explotación o proporción del valor generado por el trabajo que es apropiada por el acopiador debería de medirse la relación entre el plusvalor y el capital variable. Pero cuando las calificaciones laborales son heterogéneas las tasas de explotación son desiguales. Estas habrian de medirse entonces dividiendo el plusvalor generado con el capital variable desembolsado correspondiente a cada categoría laboral incorporada en el producto final.

33 El flete de los cueros lo fija Azara, en 1801, en 4 reales, y Concolorcorvo, en 6 reales desde Córdoba, desde Santa Tecla costaba 5 reales, desde las puntas del Tacuari costaba

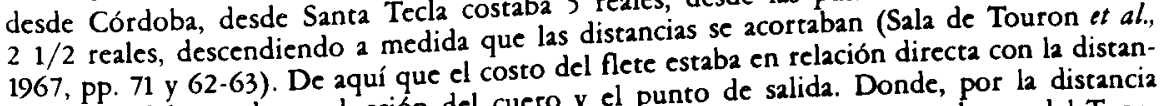
cia entre el lugar de producción del cuero y el punto de salida. Donde, por la distancia extrema, el costo del flete se devoraba las eventuales ganancias, como era el caso del Tucumán o Cuyo, el cuero se lo procesaba en curtiembres, como materia prima para la fabricación de suelas y cordobanes. El flete fluvial a través de lanchones desde de la China hasta Buenos Aires, alcanzando promedio entre re marítimo de Buenos Aires a
(AGN, Sala IX, Hacienda, leg. 41, exp. 1038, f. 2), y el flete mo tiempo de paz hasta 20 reales Cádiz fluctuaba desde 4 reales plata por cuero de 35 , leg. 26, exp. 653, f. 10). El recargo del plata en tiempo de guerra (AGN, Sala IX, Hacienda, leg. 26, exp. flete en las carretas y luego el de una navegación lel grano. El alto costo del flete para los no podían remediarse, dado el bajo valor relas de los centros urbanos, hacia que muchos labradores prefirieran afrontar el pago de arrendago del arrendamiento rural estaba expuesto poblados, antes que migrar a la frontera. El pago diferencial. Este mecanismo, en lugar de también en ese entonces al mecanismo de la reneraba a través del precio del arrendamiento. funcionar con el precio de venta del cuero, operáxima regulaba los arrendamientos y, por El costo del arrendamiento de la parcela más proximarcelas de los alrededores. El arrenda. consiguiente, la rentabilidad neta de todas las otas podía obtener un beneficio equivalente, tario de la parcela más próxima consideraba quaban los arrendatarios de parcelas más alejapagando un arredamiento mayor que el que pán pronto obligados a pagar similares arredamiendas de Buenos Aires. Estos últimos se veian pronterlo por el alto costo del flete y aun cuantos, aunque no estuvieren en condiciones de hacelo por de todo su beneficio. Algunas pardo, al continuar subiendo los arrendamientos, leto, y otras, al no suministrar renta, y sí un celas muy alejadas se abandonaban por complotadas por sus propietarios. Ya en 1635, Diego corto beneficio, únicamente podían ser exica una regiduría, arrendó una chacra en el pago de de Roxas Briones, quien también adquiriera una Domingo Griveo, el tutor de los hijos de Monte Grande (actual San Isidro) de manos des (AGN, Sala IX, Escribanías Antiguas, v. 21, Isidro Cebrián, por el término de cinco años (AGN, afectaba también el nivel de las inverf. 401). La extensión del contrato de artendami era la oportunidad de evitar un incremento siones. Cuanto más largo era el contrato, mayor era podía revertir en cierta clase de inveren el pago del arrendamiento, posibilidad ésta que pod el período más extenso fue Diego sión. El chacarero que logró arrendar una chacra por enacra en Monte Grande en $\$ 10$ Freire, en 1636. Freire arrendó a Domingo Santos una Escribanías Antiguas, v. 22, f. 477). anuales por el término de diez años (AGN, Sala 1X, Escribania 
Las provisiones mediante las cuales se avituallaba al personal de las vaquerías promediaba a razón de una libra de yerba de palos y dos libras y media de tabaco colorado por mes por peón, por un precio que en 1769 estaba a 20 reales cada arroba de yerba y $\$ 41 / 2$ cada arroba de tabaco ${ }^{34}$. Los volúmenes de tabaco y yerba consumidos por la población de la campana se pueden estudiar en forma indirecta a través de la estadística anual de los cueros producidos y/o exportados. Si tenemos en cuenta que el precio de la yerba fluctuaba entre 5 reales por arroba, o $\$ 41 / 2$ cada tercio, en 1757 , y 20 reales por arroba en 1765 , o $\$ 16$ cada tercio en 1773 , y que el precio del tabaco fluctuaba entre 16 y 32 reales la arroba, y que entre todos, vaqueros, caballerizos y peones barraqueros (habría 2.000 hombres en la Banda Oriental en 1784 ), alcanzaban a recibir cerca de $\$ 40.000$ anuales en retribución de su trabajo en las corambres, que se consumían en un 60 por 100 en yerba de palos y en un 40 por 100 en tabaco colorado, podríamos decir que las regiones rioplatenses productoras de cuero demandaban anualmente entre 100.000 y 200.000 arrobas de yerba y entre 40.000 y 80.000 arrobas de tabaco $^{35}$. Esta primitiva estimación no resultaría antojadiza si observamos que el mismo Azara menciona un promedio de 196.000

\footnotetext{
También en este mismo período se registró una intensa especulación en tierras de "pan llevar", al extremo de incrementarse su renta más del cien por cien en menos de una década. Lamentablemente, los archivos notariales guardan muy pocos ejemplares de estos contratos. La mayoría de estos contratos se registraban en la Alcaldía de Hermandad (Justicia de Paz). Por ejemplo, en 1630, una chacra fue arrendada en $\$ 20$ anuales por el término de cuatro años (AGN, Sala IX, Escribanías Antiguas, v. 16, f. 252). Diez años más tarde, en 1640, Isidro Cebrián de los Cobos arrendó una chacra más chica en Monte Grande, a Juan de Pintos, en $\$ 50$ por el término de un año. Supuestamente, aquellos terratenientes que no eran capaces de operar sus chacras por sí mismo elegían arrendarlas o darlas en aparcería antes que venderlas. Pero estos arrendatarios tampoco solían ser los productores directos, pues, por lo general, se trataba de comerciantes que a los efectos de la producción agrícola contrataban mano de obra asalariada. Por ejemplo, Diego de Roxas Briones, el arrendatario citado, no trabajaba su tierra con su propia fucrza de trabajo familiar. En cambio, Roxas trabajó su chacra empleando, entre 1635 y 1638, seis trabajadores indígenas [Saguier (1986), tabla 3]. No obstante esta aparente relación social-capitalista, Roxas Briones fracasó en volverse un auténtico arrendatario capitalista. Este fracaso era debido a la imposibilidad de disminuir la renta fundiaria y en superexplotar el trabajo indígena. Más aún, cuando los precios del trigo y la harina cayeron debido a la quiebra de relaciones con Portugal y sus colonias, las ganancias también cayeron. Como la tasa de ganancia media disminuyó drásticamente, los arrendatarios no pudieron pagar ni la renta ni los salarios de los indígenas. Consecuentemente, los terratenientes debieron comenzar a trabajar las tierras por sí mismos. [Acerca de las razones del fracaso de una típica clase arrendataria en el Buenos Aires colonial, véase Manso et al. (1983), 33.]

${ }^{34}$ AGN, Sala IX, Hacienda, leg. 4, exp. 61, f. 329.

35 En su correspondencia con el virrey Loreto del 12-IX-1781, Juan Angel Lazcano asegura que en la faena que se hacía de ganados misioneros en la Banda Oriental *... pasaban de mil hombres los que empleaba en hacer faenas de cueros" [Pereda (1938), 188-218; citado por Pivel Devoto (1957)].
} 
arrobas que salen de Asunción en el quinquenio $1788-1792^{36}$. Considerando que cada peón acondicionaba entre 50 y 100 cueros por mes, según la intensidad de la vaquería, consumiendo en víveres en dicho período una libra de yerba de palos y $21 / 2$ libras de tabaco en rama, y que una libra de yerba costaba entre $1 / 5$ y $4 / 5$ de real y que $21 / 2$ libras de tabaco costaban entre $11 / 2$ y 3 reales, concluiremos que el acopiador insumía como gasto variable para manutención de cada peón mientras durara la vaquería entre $17 / 10$ real y $34 / 5$ real cada 50 ó 100 cueros. La provisión de vituallas era imprescindible, al extremo que lo primero que hacía un hacendado para iniciar una tarea, ya se tratase de un rodeo o una corambre, era arracionar sus peones con tabaco y yerba, pues de lo contrario no hallaba jornaleros.

Entre las causas por las cuales la campiña se hallaba en 1783 con muy pocos hacendados que tuviesen rodeos mansos, un Fiel Ejecutor denunciaba: 1) la escasez de mano de obra, y 2) la destrucción del terneraje. La primera, que es la principal, se debe al hecho de no hallarse peones que se quisieran conchabar por meses corridos, debido a que "... sólo se conchaban cuando los conductores del abasto van a correr el ganado alzado" ${ }^{37}$. Esto ocurría por cuanto los hacendados

... los abrigan dándoles de comer teniendo 4, 5, y 6 en su casa, sin destino alguno, manteniéndose estos dichos peones de robos de ganados y caballos ${ }^{38}$.

Careciendo los hacendados de mano de obra fija,

... para entregar los novillos se ven en la precisión de pagarles a los referidos peones a 10 y 12 reales al día, de los que se ocupan en dicha corrida, que con estos costos que tienen el riesgo de la pérdida del ganado, sobre el abono que hacen aquí de $\$ 2$ por cada novillo, les suele salir puestos en los corrales muy cerca de 43 se manifiesta los perjuicios que a la causa pública infieren los que abrigan dichos peones y son causa de que no se conchaven por años o temporadas ${ }^{39}$.

La vaquería o corambre era un trabajo puramente estacional. Las matanzas se practicaban al igual que los rodeos, para marcar la hacienda en los meses de mayo, junio y julio, cuando los campos estaban libres de car-

\footnotetext{
36 Garavaglia (1983), 84.

37 AGN, Sala IX, Hacienda, leg. 23, exp. 555, f. 55

38 Ibidem.

39 Ibidem.
} 
dos y no había riesgo en maltratar terneros recién nacidos por estar estos meses fuera del tiempo de la parición. En los meses de verano no se podía herrar por la corrupción o riesgo de agusanarse "que le entra a los animales por el calor del yerrow. Tampoco en esta estación se podía vaquear, o apartar ganado para el pago del diezmo de cuatropea, por la abundancia de cardales y, además, por ser tiempo de cría o de parición, en que cualquier movimiento del ganado ponía en peligro de muerte a las crías, las que, debido a su endeblez física, no estaban en condiciones de seguir a sus madres en las disparadas provocadas por los vaqueros. Como hemos aclarado antes, los faeneros clandestinos carecian de tales escrúpulos. Pero no sólo los faeneros clandestinos faltaban el respeto a la naturaleza. También los indios se comportaban inescrupulosamente. En la propuesta citada, Juan Bautista Dargain expresaba que

... se impedirá el destrozo del ganado hembraje, que sin consideración hacen los faeneros changadores con el fin de aprovecharse del cebo y grasa, particularmente los indios que no habiendo quien lo impida matan las bacas preñadas sólo con el fin de comer el ternero a que son apasionadísimos,

en lugar de matar los toros crecidos, "... que no sirven para otra cosa que para consumir los pastos, y aún impedir los procreos ${ }^{40}$.

El problema se presentaba cuando las corambres eran practicadas por los hacendados con hacienda alzada, ya sea en campos propios o realengos. El resultado de estas corambres era, para cada hacendado que la practicaba, inmensas pilas de cueros sin marcar y, lo que era peor, herradas con marcas heterogéneas. En la estancia de La Mariscala, la hacienda no se herraba y los cueros hechos se admitían por orejanos por sobreentenderse la imposibilidad de herrarlos dado el inmenso número de los ganados alzados y la enormidad de las distancias a recorrer. Por otro lado, en tiempos de seca y falta de pastos, aun en las estancias más próximas a los pueblos, los ganados se alzaban y se marchaban a las serranías, donde abundaban los pastoreos y aguadas y donde era imposible la yerra. De modo que las autoridades civiles admitían la posibilidad de otorgar guías a los cueros orejanos cuando éstos procedían de ganados alzados. Pero éste no era el caso cuando, al cuestionarse la naturaleza alzada o realenga del ganado, los cueros resultan. tes podían considerarse mostrencos y no orejanos. Los primeros, a diferencia de estos últimos, debían ser comisados y rematados al mejor postor en almoneda pública. En estos casos se estaba al diezmo que cada uno pagara,

40 AGN, Sala IX, Hacienda, leg. 66, exp. 1769, f. 1. 
por lo que se nombraba por parte del juez personas inteligentes en la mate$\mathrm{ria}^{41}$

En el caso de corambres con hacienda de marcas heterogéneas, al ser vendidos los cueros a los acopiadores, se prestaban a ser denunciados por los dueños de las marcas, al extremo de serles secuestrados los mismos por la autoridad respectiva. Por cierto que, de esta mezcolanza de cueros con marcas distintas, quienes sacaban ganacias extraordinarias eran los faeneros clandestinos, los gauderios y los pulperos sin escrúpulos, que reducían cuanto cuero les llegaba a sus manos. Para impedir este relajo, las autoridades dictaron en 1792 un bando exigiendo a los compradores de cueros la contramarca correspondiente a cada cuero adquirido. Esto les significaba a los comerciantes una dificultad imposible de remontar. Indignado por los perjuicios que le irrogaba este bando, un comerciante declaraba en 1792 que

... el comercio de los cueros se hace comprando a los criadores a 4, a 6, a 8, o a más número y que éstos tienen sus estancias en las dilatadas campañas de aquel territorio distantes unas de otras 15, 20 ó 30 leguas y que le es imposible al comprador andar con los cueros que a comprado de estancia en estancia para contramarcarlos sin hacer unos gastos que importan diez tantos más que el valor que tengan estos cueros conducidos a esta Capital y así o le sería indispensable al comprador abandonarlos por inútiles o conducirlos para ser secuestrados sin haber delinquido en su adquisición ${ }^{42}$.

Si bien los jornales de la mano de obra a destajo empleada en las vaquerías sufrieron una notable mejoría, de 4 reales al día en tiempos del virrey Ceballos a 6 u 8 reales doce años después, no podríamos afirmar con certeza, por carecer de la información respectiva, que los jornales rurales siguieran las oscilaciones del precio del cuero ${ }^{43}$. El jornal por cada mil cueros faenados aumentó de $\$ 50$ a comienzos del siglo XVIII (1723) a $\$ 62$ 1/2 en el año de mayor baja del precio del cuero (1769) ${ }^{44}$. Es decir, el jornal aumentó en medio siglo $\$ 121 / 2$ sobre un básico de $\$ 50$, lo que es decir un 25 por 100. Quince años después, los salarios rurales experimentaron un nuevo repunte aún más considerable. Felipe Flores y Francisco Sandoval

4 AGN, Sala IX, Tribunales, leg. C-5, exp. 9, f. 50v

42 AGN, Sala IX, Hacienda, leg. 64, exp. 1730.

43 Levene (1962), 328.

44 Coni (1930). 
(alias Chumingo), socios de ejercicio banqueros, faenaron por orden de Antonio Pereyra a favor de la Administración de los Pueblos de Misiones, y en el paraje El Daymán, 6.285 cueros cotizados a 3 reales cada uno, en los cuales trajinaron tres barraqueros a $\$ 10$ mensuales cada uno, insumiendo $\$ 888$ que, deducidos de los $\$ 2.357$ que importaron los cueros, significaron $\$ 739$ para cada uno de los dos vaqueros, o el equivalente a $\$ 225$ cada mil cueros, más del triple de lo devengado por un baquero quince años atrás ${ }^{45}$.

Si bien hemos comprobado en la campaña de la Banda Oriental la existencia de una inflación del salario a destajo o por piezas, no lo hemos comprobado aún con respecto a los salarios fijos. De todos modos, la inflación del salario a destajo fue función del boom del cuero y, tan pronto como se poblaron las tierras realengas y se reglamentó la marca y la contramarca, esta inflación del salario fue desapareciendo. Aquellos acopiadores de cueros que supieron valerse de los reservorios de mano de obra indígena o miliciana también supieron acumular grandes diferencias, con las cuales engrosaron las filas de la nueva burguesía naciente.

45 AGN, Sala IX, Hacienda, leg. 38, exp. 973, f. 5. 


\section{BIBLIOGRAFIA}

Agosti, Héctor P. (1951): Echeverria, Buenos Aires: Futuro.

AMArAl, Samuel (1987): "Rural Production and Labour in Late Colonial Buenos Aires", Joumal of Latin American Studies, 19, 235-278.

ARias Divito, Juan Carlos (1976): "Dificultades para establecer la renta de tabaco en Paraguay", Anuario de Estudios Americanos, 33, 1-17.

ARICó, José (1987): "Gramsci y el jacobinismo argentino", La Ciudad Futura, 6, 18-20.

Assadourian, Carlos Sempat, et al. (1980): Mineria y espacio económico en los Andes. Siglos XVI. $X X$, Lima: IEP.

ASSUNCAO, Fernando (1978): El gaucbo: estudio sociocultural, Montevideo: Dirección General de Extensión Universitaria.

Barrios Pintos, Aníbal (1967): De las vaquerías al alambrado, Montevideo: Ed. del Nuevo Mundo.

BAUER, Arnold J. (1979): "Rural Workers in Spanish America: Problems of Peonage and Opression", Hispanic American Historical Review, 59 (1), 34.63.

Brito Stefano, Rogelio (1953): "Dos noticias sobre el estado de los campos de la Banda Oriental al finalizar el siglo XvilI, Revista Histórica, t. 18.

CONI, Emilio (1930): Historia de las vaquerias del Río de la Plata, Madrid.

Chevalier, François (1952): La formation des grandes domaines au Mexique: Terre et société aux XVle-XVIIe siecles, París.

DE RAMÓN, Armando (1978): Historia urbana. Una metodología aplicada, Buenos Aires: CLACSO, Ed. SIAP.

DOS SANTOS, Theotonio (1972): Socialismo o fascismo. El nuevo carácter de la dependencia y el dilema latinoamericano, Buenos Aires: Ed. Periferia.

FloResCANO, Enrique (coord.) (1985): Orígenes y desarrollo de la burguesia en América Latina, 1700-1955, México: Ed. Nueva Imagen.

FURTADO, Celso (1969): «Desarrollo y estancamiento en Arayos de interpretación crítica, Santia-

Garavaglia, Juan Carlos (1983): Mercado intemo y mercado colonial, México: Ed. Grijalbo.

GelmaN AIZEN, Jorge (1987): "Sobre esclavos, peones, gauchos (manuscrito inédito). y los trabajadores en una estancia colonial re Old Problem and the Same Source: The

Gelman, Jorge (1989): "New Perspectives Colonial Río de la Plataw, Hispanic American HistoGaucho and the Rural History
rical Review, 69: 4, 715-731.

les (1967): Los aztecas bajo dominio español, 1519-1810, México: Siglo XXI.

(1966) : Estructuras de colonización y modalidades del tráfico en el Pacífico Sur hispanoamericanom, Historia y Cultura.

Kalmanovitz, Salomón (1983): El desarrollo tardio del capitalismo. Un enfoque crítico de la teoría de la dependencia, Bogotá: Siglo XXI.

KaY, Cristóbal (1977): "The Latin American Haciendalschaft Lateinameikas, Colonia, 14, te la historia económica del Río de

LeVene, Ricardo (1952, 1962): "Investigaciones acercas de Ricardo Levene, Buenos Aires, II. la Platam, en Academia Nacional de la Historlo (1983): "Manuel de Pinazo: perfil econó-

Manso, Julie; Ríos, Emilio, y CAlDERON, Pabin Cuademos de Historia, Ateneo de Estudios mico y social de un hacendado del siglo Aires, v. 4.

Históricos Manuel Belgrano, Buenóctica del comercio por intermediario en el tráfico Martínez Gijón, José (1970): "La práctica del comercio por interio de Derecho Español, 40, 5-43.
con las Indias durante el siglo XVI*, Anuario de Historia del 
Mayo, Carlos A. (1984): „Estancia y peonaje en la región pampeana en la segunda mitad del siglo XVIII", Desarrollo Económico, 92.

- (1987): "Sobre peones, vagos, malentretenidos. El dilema de la economía rural rioplatense durante la época colonial, Anuario (Tandil: Universidad Nacional del Centro, IEHS), II.

PEREDA, D. Stembrino E. (1938): Paysandú en el siglo XVIII, Montevideo.

Pivel Devoto, Juan E. (1957): Raíces coloniales de la revolución oriental de 1811, Montevideo: Ed. Medina.

PORTO, Aurelio (1943): Historia das missoes orientais do Uruguai, Río de Janeiro: Ministerio da Educação e Saude.

Prado Junior, Caio (1961): Historia economica do Brasil, Sāo Paulo.

RAMfREZ-HORTON, Susan (1985): "La élite terrateniente de la costa norte peruana: una historia económica y social de Lambayeque en la epoca colonial, 1700-1821", en Florescano (1985).

SAGUIER, Eduardo R. (1986): "Economic Impact of Indian Immigration and Comercial Capital on the Formation of a Colonial Labor Force. The Case of Buenos Aires in the Early Seventeenth Centurym, Revista de Historia de América, México, 101, 65-104.

- (1990): "La inflación de ganancias como resultado del comercio a larga distancia. El caso del Río de la Plata a fines del siglo Xvilı (inédito).

SAla DE TOURON, Lucía, y otros (1967): Estructura económico-social de la colonia, Montevideo: Ed. Pueblos Unidos.

Salvatore, Ricardo, y Brown, Jonathan C. (1987): "Trade and Proletarianization in Late Colonial Banda Oriental. Evidence from the Estancia de las Vacas, 1791-1805", Hispanic American Historical Review, 67, 3, 431-459.

- (1989): "The Old Problem of Gauchos and Rural Society", Hispanic American Historical Review, 69: 4, 733-745.

TerRerA, Guillermo Alfredo (1970): El caballo criollo en la tradición argentina, Buenos Aires: Círculo Militar.

Villalobos, Sergio (1959): Comerio y contrabando en el Rí de la Plata y Cbile, Buenos Aires: EUDEBA.

ZavalA, Silvio (1968): El mundo americano en la época colonial, México. 